\title{
Reunião de regentes, de Selma Lagerlöf
}

João Joakim T. Wagner

Palavras-chave: Monarkmötet, Selma Lagerlöf, Literatura sueca

Selma Ottilia Lovisa Lagerlöf, romancista e contista sueca, foi agraciada com o prêmio Nobel de literatura em 1909, sendo a primeira mulher a receber esta distinção. Em 1914 tornou-se também a primeira mulher a integrar a Academia Sueca. Está entre os nomes mais importantes e conhecidos da literatura sueca e é considerada o ponto culminante da tradição do conto de autoras femininas iniciada por Frederika Bremer (1801-1865). Em seu trabalho, Lagerlöf também seguiu a trilha da participação de autores voltados para o público adulto que também dedicam atenção à literatura infantil, inaugurada por Zacharias Topelius (1818-1898).

Nascida em 20 de novembro de 1858, em Mårbacka, na província de Värmland, no sudoeste da Suécia, Selma era filha de Erik Gustav Lagerlöf, oficial reformado do exército, e Louise Wallroth. Recebeu formação de professora entre 1882 e 1885 e desempenhou essa função na escola elementar para meninas, em Landskrona, até 1895.

Inicialmente, Selma Lagerlöf conduziu o trabalho de autora paralelamente ao trabalho de professora, até se mudar, em 1895, para a cidade de Falun, na província de Dalarna, sul da Suécia, quando passou a viver apenas de seu trabalho como escritora.

1 Mestrando em Língua e Literatura Alemã pela Universidade de São Paulo. Graduado em Química pela Universidade de São Paulo em 1990, concluiu em 2016 graduação em Letras, habilitação dupla Português e Alemão, igualmente pela Universidade de São Paulo. Contato: joakimwagner@yahoo.com 
Com a aproximação da Segunda Guerra Mundial, a autora ajudou artistas e intelectuais judeus a escaparem da perseguição nazista. Apesar de isto ser de conhecimento das autoridades nazistas, seu nome não foi incluído nas listas de autores proibidos, e obras suas eram distribuídas às tropas. Selma Lagerlöf faleceu em 16 de março de 1940, na mesma casa em Mårbacka onde havia nascido, em meio a seus esforços de fazer chegar assistência aos civis finlandeses que viviam sob o efeito dos bloqueios decorrentes da guerra.

Em sua obra, com estilo bastante próprio, Selma Lagerlöf recorre extensamente a lendas nórdicas, elementos do folclore, histórias e narrativas orais de sua cidade natal e, frequentemente, também elementos retirados tanto da História quanto de sua própria biografia. Estes elementos são amalgamados em textos nos quais as fronteiras entre o real e o imaginário muitas vezes se tornam difusas e incertas. Dentre suas obras mais conhecidas destacam-se especialmente dois romances:

- Gösta Berlings Saga (A Saga de Gösta Berling), de 1891. Assinala a estreia literária da autora. Trata das guerras napoleônicas, já trazendo o rompimento de Selma Lagerlöf com o realismo e o naturalismo prevalentes à época. Inicialmente este romance enfrentou receptividade ruim.

- Nils Holgersons underbara Resa genom Sverige (A maravilhosa viagem de Nils Holgersson pela Suécia), romance em dois volumes lançado em 1906-1907. Foi escrito sob encomenda, com o objetivo de ser usado como material de apoio escolar para ensino de geografia sueca e ainda hoje se mantém como leitura popular entre jovens, na Suécia e em outros países. Sua primeira edição em português (europeu) data de 1936.

No contexto específico deste trabalho, é importante considerar-se também o romance Kejsarn av Portugallien (O imperador de Portugália - tradução minha), publicado em 1914 e com tradução em português (europeu) de 2006. Observa-se a existência de um importante diálogo entre este romance e o conto "Monarkmötet" (Reunião de Regentes), objeto deste trabalho.

Kejsarn av Portugallien se passa no final do séc. XIX e retrata a vida do camponês Jan Andersson, a esposa Kattrinna e sua filha Klara, por quem ele tem profundo amor. Quando Jan recebe a cobrança de uma dívida, de legitimidade no mínimo duvidosa, sua jovem filha Klara dispõe-se a buscar trabalho em Estocolmo. Lá ela consegue juntar o dinheiro necessário e o envia ao pai. A prolongada ausência da filha e a escassez de notícias dela fazem com que Jan acabe por cair em depressão e se perder progressivamente num mundo de delírios. Usando um velho barrete na cabeça, um cajado adornado em prata e estrelas de papel ao peito, ele passa a 
se autointitular imperador João de Portugália. Nesta condição, e escudado pela fama de loucura, ele passa a ter comportamentos estranhos e a fazer comentários críticos e muitas vezes inconvenientes que, sob outras circunstâncias, não seriam tolerados vindos de um camponês pobre. Também conta numerosas histórias de seu país feliz, Portugália.

No conto "Monarkmötet", que integra o primeiro volume de Troll och människor, uma coletânea de textos curtos publicada em 1915, Selma Lagerlöf retoma o personagem João de Portugália/Jan Andersson para relatar o encontro do imperador com o então monarca do Reino Unido da Suécia e Noruega, Oskar II, durante uma passagem deste pela província de Värmland, que faz fronteira com a atual Noruega. A ação descrita ocorre na década de 1880, na estação ferroviária de Kil, que integrava o trecho pioneiro de via férrea na Suécia, instalado nos anos 1850. Kil é, ainda hoje, um importante entroncamento ferroviário.

Na década de 1880 já se observavam sinais da crescente tensão entre Suécia e Noruega, gerada pela busca norueguesa de romper a união política estabelecida entre os dois países como consequência das guerras napoleônicas. Anos mais tarde, as tensões escalaram a ponto de alcançarem a efetiva mobilização de tropas e, então, o rei Oskar II formalizou a aceitação da dissolução formal da união e abdicou da coroa norueguesa em 1905. 


\section{Monarkmötet}

\section{Selma Lagerlöf}

Det var i början av åttitalet vid en järnvägsstation i Värmland, där kungen skulle resa förbi. Man hade klätt med grönt och med blommor, det svajade fanor i luften, och allt folk, som fanns i hela trakten, hade strömmat dit.

Och medan människorna väntade på att kungatåget skulle komma, var de både glada och lyckliga. De stod och gjorde upp för sig hur de skulle ta emot majestätet. De skulle ropa hurra, och de skulle ge honom blommor, och de skulle sjunga. Ja, här vid Kils station skulle han bli så mottagen, att han aldrig skulle förglömma det.

Men när tåget brusade in på stationen, blev det en stor oro strax i början, därför att alla ville tränga sig fram, så att de skulle komma i närheten av kungens vagn. Det var ju nu, som de skulle ha ropat hurra, men det glömde de rent bort, av ängslan för att de inte skulle kunna armbåga sig fram till någon bra plats.Men en var det, som varken sprang eller trängdes, utan bara stod stilla och höjde käppen med den stora silverknappen för att slå takt, och som hurrade så, att det genljöd i alla väggar.

Det var en liten karl, som hade en hög, grön kaskett på huvudet och hela bröstet fullsatt med stjärnor av både guld- och silverpapper.

Och det kan nog hända, att kungen och de, som var med honom, lade märke till att det fanns en karl i hela hopen, som var lugn och bar sig rätt åt, när alla de andra var som stolliga.

Inte blev det något av med sången, för se, skolbarnen, som skulle sjunga, de hade i trängseln blivit förskingrade åt alla håll, och inte heller fick kungen några blommor. De, som stod med buketter i händerna, hade blivit så förstenade av blyghet, att de inte kom sig för att gå fram till honom.

Det var bara en karl, som inte förlorade besinningen, och just i detsamma som kungen kom ut ur järnvägsvagnen och steg ner på träbron framför stationshuset och stod där och såg både bekymrad och ledsen ut, därför att han hade fått ett så dåligt mottagande, så banade sig den karlen väg fram till honom.

«Go’dag, min snälla Oskar den andre!« sa karlen, och därmed tog han av sig kasketten och sträckte fram handen.

Kungen såg riktigt belåten ut. Han blev nog glad över att här vid Kils station fanns någon, som inte var blyg och inte hade blivit yr i mössan, utan visste hur han skulle bete sig.

«Go’dag, du!« sa kungen tillbaka. «Vad är du för en?« 
Då svarade karlen, som sanningen var: «Jag är kejsar Johannes av Portugallien.« Men han sade det med en så mild och len röst, som det var honom möjligt, för det kunde ju hända, att kungen var van att alltid vara den första här i landet, och att han inte skulle tycka om, att det fanns en, som stod lika högt som han.

Det var nog flera, som var rädda för att det kunde förhålla sig så, för de, som stod närmast, ryckte honom i rocken och ville ha bort honom, liksom om de inte var säkra på hur detta mötet skulle sluta. Men kungen var inte av det slaget, som inte kan tåla sin like. Han bara vinkade åt dem, att de skulle hålla sig stilla.

«Kors i alla mina dar!« sa han och lät riktigt glad i rösten. «Är det en ämbetsbroder, som jag har råkat ut för?«

«Ja, vi har väl ungefär samma börda te å bära, « sa då han, som var kejsare, så ödmjukt, så. För se, att skryta över att han hade ett högre ämbete, han, än den andre, det skulle han aldrig ha kunnat förmå sig till att göra.

«Jag hör, att du har den rätta uppfattningen av saken,« sa kungen. «De, som inte har prövat på vad det vill säga, de tror, att vi kungar inte har något annat att göra än att sitta på en tron med krona på huvudet och spira i handen. Men bli kung bara, så får man se på annat. Tänk, att det ska kännas tungt också till att vara kejsare av Portugallien!« lade han till med en suck.

«Det har ju inte var’t så värst tungt hittills, « sa då kejsarn, för han ville förstås inte skämma ut det egna landet. «Vi har ju fått behålla freden, och det är ändå det förnämsta goda."

Det syntes allt, att kungen blev storbelåten.

«Det är inte fritt, att inte du förstår dej på regeringskonsten,« sa han. «För se, att hålla fred, det är både det första å det sista. Freden är för riket detsamma, som hälsan är för kroppen.«

Kejsarn fick allt lov att vända sig om och se sig omkring, när kungen sade detta. Folk stod molstilla i en vid krets, och inte en enda tordes röra sig ur fläcken bara för att inte mista ett ord av det, som han och kungen sade till varandra. Det hade allt varit bra, om han hade tänkt på att ta Kattrinna med sig. Åtminstone skulle han ha önskat, att någon enda Svartsjöbo, och helst någon av herrkarlarna, hade varit tillstädes.

Men på samma gång hörde han noga efter vad kungen sade och var strax färdig att svara honom.

«Ja, nog är freden e god sak,« sa han.

«Men en kan inte veta hur länge vi får behålla honom, för i söndags, när jag skulle gå hem från gudstjänsten i Svartsjö kyrka, kom jag i sällskap med två främmande karlar. A den ena åv dom var Kriget, å den andra var Döden.«

Det var så vanligt för honom, som var kejsare av Portugallien, att råka alla slags konstigheter och besynnerligheter, så att inte hade han trott på att det, som han berättade om mötet på kyrkvägen, skulle bli betraktat som något försök att förhäva sig. Men det 
måtte det ändå ha blivit, för nu började de på att rycka honom i rocken igen, de, som stod bakom, och ville ha honom att tiga. Men kungen förstod nog, att ett sådant där möte, det var som ingenting att räkna för en sådan som han, och han vinkade åt folket, att de skulle hålla sig stilla.

«Vad är det du säjer?« sa han. «Har du varit ute å gått i sällskap med Döden å Kriget? Jag kan just undra hur de två såg ut.«

«Di var väl mest lika ett par fattiga vedhuggare,« sa kejsarn, «för di gick med stora timmeryxor på axeln. När jag hade fått veta vilka di var, så fråga’ jag dom förstås vad di var ute i för ett ärende, å då sa di, att di gick omkring å drog ihop bränsle te stora bål. Di vandra' från land te land, sa di, å bara di blev färdiga, så skulle di sätta eld på hela världen.«

«De kunde väl aldrig tänka på att lägga opp något bål i det här landet heller,« sa kungen, och alltjämt smålog han och såg glad ut.

«Di trodde allt, att det skulle bli klent medförtjänsten här i landet, « sa kejsarn.

«Men di skulle ändå göra ett försök på västkanten. För där trodde di att det var möjligt, att di kunde samla ihop bränsle te ett ordentligt bål.«

Men tänk, att med detsamma som kejsarn hade talat om västkanten, så rättade kungen upp sig och blev allvarsam.

«Nej,« sa han helt tvärt och höjde rösten, så att det han sade kunde höras till varenda människa på Kils station, «det kommer inte att lyckas för dem. Det kommer inte att bli något arbete för Krig å Död åt det hållet, så länge jag lever. För tror du, att jag vill vara kung över folk, som jag skulle vara tvungen att underlägga mej med makt å våld?

Jag vet väl, att det är svårt att hålla fred, men hellre vill jag offra kronan, än att jag skulle släppa lös eld å plundring över fredliga städer å byar å se åkrar nedtrampade å se människor döda å lemlästade. Jag ar sett hur det har gått framåt i mina två länder under min regering, « sa han och kastade en stor, ljus blick omkring sig, «å aldrig ska jag vara med om att förstöra det, som det har varit min största glädje att se växa.«

När kungen hade sagt detta, hade han fått glans över ansiktet, och rösten skälvde till så vackert, att man hörde, att han menade vad han sade. Men kejsarn hade ju aldrig väntat mindre av honom, och nu lade han handen på armen på honom.

«Min snälla kung Oskar! Min snälla kung Oskar!« sa han för att lugna honom. «Ja, sätt mej på prov bara!« sa kungen och såg än stoltare ut än förut. Men folket runt omkring tyckte, att kungen talade så vackert, att de fick tårar i ögonen, och rätt som det var, var det en, som gav sig till att ropa hurra.

Med detsamma tog de upp ropet över hela Kils station, och nu viftade de åt honom med hattar och näsdukar, och nu sjöng de, och nu kom de med blommor, för se, nu var de inte rädda för honom mer, nu hade han värmt dem. Nu fick han allt det, som de inte hade kommit sig för med att ge honom, då de först såg honom. 
Men medan kungen av Sverige blev hyllad och firad, stod kejsarn av Portugallien alldeles stilla en stund och såg på med stora ögon. Sedan smög han sig så stilla och tyst bort genom folkhopen.

Inte för att han kände sig på minsta sätt missbelåten med att han hade fått göra bekantskap med en riktig kung, men nog tycktes det, att han såg bra fattig och liten och avsigkommen ut, när han gav sig i väg hem till Svartsjösocknen.

Det var mången, som gladde sig åt kungens ord vid Kils station, men just ingen trodde då, att man fick ta dem alldeles efter bokstaven.

Sedan, flera år efteråt, då man såg hur det gick, var det flera, som påminde sig samtalet, och då förstod de, att kungen hade sagt sant, och att han hade bestått provet.

Och att det var sant med dem, som gick omkring och samlade ihop bränsle till världskriget, det har vi också sett.

Men när visar sig för oss den store fridsfurste, som inte kan se människor lida och byar brännas och åkrar nedtrampas? När kommer han, som vill offra kronans ära och glans för att ge den förtvivlade världen fred? 


\title{
Reunião de regentes
}

\author{
Selma Lagerlöf \\ Tradução do sueco: \\ João Joakim T. Wagner
}

Foi no início dos anos 1880, em uma estação ferroviária na província de Värmland, ao sudoeste da Suécia, por onde o rei iria passar. A estação estava toda decorada com folhagens e com flores, bandeiras tremulavam ao vento e todo o povo da vizinhança havia acorrido.

Felizes e contentes, as pessoas esperavam a chegada do trem real. Paradas ali, ficavam imaginando como receberiam Sua Majestade. Dariam vivas e entregariam flores e cantariam. Isso mesmo. Aqui, na estação de Kil, ele teria uma recepção que jamais iria esquecer.

Mas, quando o trem chegou, ruidoso, na estação, logo houve grande agitação, pois todos se acotovelavam para chegar perto do vagão do rei. Era agora que deveriam ter dado vivas, mas esqueceram-se completamente, por angústia de não conseguirem arranjar um bom lugar.

Mas havia um que não corria nem se acotovelava. Simplesmente ficou parado e ergueu o bastão cerimonial com um grande enfeite de prata e gritou vivas tão altos que ressoavam por todas as paredes. Era um sujeito pequeno, com um casquete verde e alto na cabeça e com o peito todo coberto de estrelas de papel dourado e prateado.

E é bem capaz que o rei e os que estavam com ele tenham reparado haver um sujeito que estava calmo e se portava bem e com compostura, enquanto os outros pareciam desvairados.

Não houve cantoria, pois, veja, os escolares que deveriam cantar tinham sido dispersados aos quatro ventos pelo empurra-empurra, nem o rei recebeu flores. As pessoas que traziam os buquês nas mãos estavam petrificadas pela timidez, a ponto de que sequer pensar em se aproximar do rei.

Havia apenas um sujeito a manter a presença de espírito que, assim que o rei saiu do vagão descendo a plataforma de madeira diante da estação ferroviária, parecendo preocupado e triste pela recepção tão ruim, se aproximou do rei.

"Bom dia, meu bondoso Oskar II!", disse o sujeito, tirando o barrete e oferecendo a mão em cumprimento.

O rei pareceu verdadeiramente satisfeito. Deve ter se alegrado por haver aqui na estação de Kil alguém que não era tímido e não havia ficado maluco, mas sabia como deveria se portar. 
"Bom dia, aí!", o rei respondeu. "E você, quem seria?"

O sujeito então respondeu, conforme a verdade:

“Eu sou o imperador João de Portugália.” Mas ele o disse com a voz tão amena e suave quanto lhe era possível, afinal, poderia bem ser que o rei estivesse acostumado a ter sempre a primazia no país e que não gostasse que existisse alguém em posição tão elevada quanto a dele.

Certamente havia várias pessoas receosas de que realmente fosse assim, pois aquelas mais próximas do sujeito o puxavam pelo casaco, querendo tirá-lo dali, como se tivessem receio do desfecho daquele encontro. Mas o rei não era do tipo que não tolera um semelhante. Apenas gesticulou para as pessoas que ficassem quietas.

"Minha nossa", disse, com a voz soando realmente satisfeito. "Será que topei com um colega de ofício?"

"Bem, acho que nóis dois tem fardos parecido pá carregá", disse então aquele que era imperador, de forma assim tão, tão humilde. Pois, veja, gabar-se de ter, ele, um cargo superior ao do outro era algo que jamais conseguiria se obrigar a fazer.

"Percebo que você tem o entendimento correto da coisa", disse o rei. "Os desconhecedores do assunto acham que nós, reis, não temos nada a fazer além de ficar sentado num trono, de coroa na cabeça e cetro na mão. Mas torne-se rei que verá de outra maneira. Imagine só o peso de ser imperador de Portugália!”, ele acrescentou com um suspiro.

"Bem, num tá assi tão terrificante de pesado até agora", respondeu o imperador, pois afinal ele não queria desmerecer seu próprio país. "Conseguimo manter paiz e isso é demais de bom."

Todos viram que o rei havia ficado muito satisfeito.

"Logo se vê", disse ele, "que você entende mesmo tudo da arte de governar", disse ele. "Pois, veja, manter a paz é a mais importante das coisas. A paz é para o reino o mesmo que a saúde é para o corpo."

Quando o rei disse isso, o imperador teve oportunidade de se virar e olhar ao redor de si. O povo estava imóvel, num amplo círculo, e ninguém ousava sair do lugar, para não perder uma única palavra do que ele e o rei diziam. Tudo estaria bem, se ao menos ele tivesse lembrado de trazer sua esposa Kattrinna. Desejava que ao menos um dos moradores de Svartsjö, de preferência algum dos poderosos, estivesse presente.

Ao mesmo tempo, ele ouvia atentamente o que o rei dizia e logo estava pronto a lhe responder.

"Sim, claro que paiz é coisa boa", disse ele. "Má num dá pá sabê quanto tempo nós consegue ficar cum ela. No domingo, eu tavínu pá casa, vortânu da missa na egreja de Svartsjö, e eu encontrei dois sujeito estranho. Um era Guerra, o ôtro era Morte."

Para ele, que era imperador de Portugália, era tão habitual encontrar todo tipo de coisa estranha e curiosa que nem imaginava ter o relato deste seu encontro ao voltar da igreja tomado por presunção. Mas é o que deve ter acontecido, pois agora as pessoas atrás 
dele voltaram a puxá-lo pelo casaco, querendo silenciá-lo. Mas o rei compreendia bem que um encontro daqueles não deveria ser levado muito a sério por alguém em sua posição e, portanto, gesticulava à multidão para que se mantivesse quieta.

"O que está dizendo?", disse ele. "Você caminhou na companhia de Morte e Guerra? Não consigo nem imaginar a aparência que têm.”

"Olha, pareciam bem com uns lenhadô pobre", disse o imperador, "carregânu uns machado grande nos ombro. Quando eu sube quem era, é claro que eu preguntei a intenção que tinha. Repondêru qui távu rondano pra juntá combustívi pruma grande pira. Disséru que vão de país em país e que quando tudo tivé pronto, vão tacar fogo no mundo tudo."

"Bem, com certeza, nunca pensariam em armar alguma pira dessas aqui neste país", disse o rei, sempre sorrindo, e parecia satisfeito.

"Disséru que achávu que o ganho por aqui ia de ser piquênu", disse o imperador, "mas que queria tentá, lá pras banda do oeste. Acreditávu que dava pra juntar combustívi pruma boa duma pira."

Mas, imagine só, assim que o imperador falou da região a oeste, o rei se empertigou todo e ficou sério.

"Não", ele disse bruscamente e erguendo a voz, para que fosse ouvido por cada uma das pessoas na estação Kil, “eles não vão conseguir o que querem. Não haverá trabalho para Guerra e Morte naquelas paragens enquanto eu viver. Ou você acha que eu quero ser rei de uma gente que eu teria de subjugar com repressão e violência?"

"Eu sei bem quanto é difícil manter a paz, mas antes renunciar à coroa que deixar à mercê de fogo e pilhagem cidades e povoados pacíficos e ver plantações pisoteadas e pessoas mortas e mutiladas. Eu observei o progresso que houve em meus dois reinos durante o meu reinado", disse ele, lançando um longo olhar benevolente em torno, "e jamais eu participaria na destruição de algo que foi minha maior alegria ver crescer."

Isto dito, o rosto do rei ficou radiante e sua voz tremeu de forma tão bela que se podia ouvir a sinceridade de suas palavras.

Mas o imperador, em momento algum, havia esperado outra coisa do rei e agora pousou-lhe a mão no ombro.

"Meu bondoso rei Oskar! Meu bondoso rei Oskar!”, dizia para acalmá-lo.

"Sim, vamos, ponha-me à prova!", disse o rei, parecendo ainda mais orgulhoso do que antes.

O povo ao redor achou tão bonita a fala do rei que ficou com lágrimas nos olhos e, de repente, alguém começou a dar vivas.

Imediatamente os vivas tomaram a estação de Kil e agora todos acenavam para o rei com chapéus e lenços e cantavam, e agora trouxeram-lhe as flores, pois, veja, já não tinham mais medo dele, pois ele havia tocado seus corações. Agora o rei recebeu tudo aquilo que eles não lhe haviam dado quando o viram da primeira vez. 
Enquanto o rei da Suécia era homenageado e festejado, o imperador de Portugália ficou parado por um tempo, observando admirado. Depois ele se esgueirou de forma muito quieta e silenciosa para fora da aglomeração.

Não que estivesse minimamente descontente por ter conhecido um verdadeiro rei, mas parecia bastante pobre e pequeno e decrépito voltando para sua casa na paróquia de Svartsjö.

Muitos se alegraram com as palavras do rei na estação de Kil, mas ninguém achou naquele momento que pudessem ser levadas ao pé da letra. Mais tarde, muitos anos depois, quando se viu como as coisas transcorreram, muitos se lembraram desta conversa e, então, entenderam que o rei havia falado a verdade e que havia passado na prova.

E que também era verdade a história sobre aqueles que andavam por aí juntando combustível para a guerra mundial. Isso também foi observado.

Mas quando vai se nos revelar o grande príncipe da paz, que não tolera ver pessoas sofrendo e aldeias sendo queimadas e plantações serem pisoteadas? Quando chegará aquele disposto a sacrificar a honra e o brilho da coroa para dar paz ao mundo desesperado?

\section{Referências bibliográficas}

ALGULIN, Ingemar. A History of Swedish Literarture. Trad. John Weinstock, Uddevalla: Bohusläningens Boktryckeri AB, 1989. Original sueco. HENRICKSON, Alf; Svensk Historia; Bonniers; 1963.

OSKAR II. In: Encyclopædia Britannica. Cambridge University Press. 1911. 20 (11th ed.), p. 346.

BOOKS AND WRITERS. Disponível em: < http://authorscalendar.info/lagerlof.htm>. Acesso em 20 de mar. 2017.

LITTERATURBANKEN. Litteraturbankens epubfiler. Disponível em http://litteraturbanken.se/\#!/forfattare/LagerlofS/titlar/TrollOchMann/sida/5/etext. Acesso em 15 de mar. 2017.

NOBEL PRIZE. Lists of Nobel Prizes and Laureates. Disponível em <http://www. nobelprize.org/nobel_prizes/literature/laureates/1909/lagerlof-facts.html>. Acesso em 15 de mar. 2017.

PROJEKT RUNEBERG. Svenskt biografiskt handlexikon. Disponível em <http:// runeberg.org/sbh/lagerlof.html >. Acesso em: 20 de mar. 2017.

PROJEKT RUNEBERG. Svensk litteratur i sammandrag. Disponível em $<$ http://runeberg.org/svlihist/lagerlof.html>. Acesso em 15 de mar. 2017.

SVERIGES HEMBYGDFÖRBUND Hitta hembygdsförening Disponível em $<$ https:// www.hembygd.se/stora-kil/sevardheterutflyktsmal/sveriges-forsta-jarnvag-2/>. Acesso em 15 de mar. 2017. 